\title{
Peripapillary retinal nerve fibre thickness in patients with primary open-angle glaucoma
}

Aleksandar Miljkovic ( $\nabla$ aleksandar.miljkovic@mf.uns.ac.rs )

Univerziteta u Novom Sadu Medicinski Fakultet https://orcid.org/0000-0003-1509-5041

Nikola Babic

Univerziteta u Novom Sadu Medicinski Fakultet

Davidovic Sofija

Univerziteta u Novom Sadu Medicinski Fakultet

Sava Barisic

Univerziteta u Novom Sadu Medicinski Fakultet

Jelena Ljikar

Univerziteta u Novom Sadu Medicinski Fakultet

Sandra Jovanovic

Univerziteta u Novom Sadu Medicinski Fakultet

\section{Research article}

Keywords: ,

Posted Date: October 25th, 2019

DOI: https://doi.org/10.21203/rs.2.16429/v1

License: (c) (1) This work is licensed under a Creative Commons Attribution 4.0 International License. Read Full License 


\section{Abstract}

Background The purpose of this study was to determine the difference in peripapillary retinal nerve fiber layer (RNFL) thickness in patients with preperimetric glaucoma and open angle glaucoma (POAG) in comparison to healthy population, as well as to determine the difference in thickness of peripapillary RNFL according to progression of the disease.

Methods In this study, 120 patients were included. On the basis of clinical finding four groups of patients were formed: group without glaucoma, early POAG group, moderate POAG group and group with preperimetric glaucoma. Complete ophthalmological examination, visual field and optic coherent tomography of peripapillar region of RNFL were performed. The collected data was entered into a specially created database on a personal account, and the statistical processing was done using the SPSS for Windows.

Results are displayed through charts and tables.Results The results showed that the thickness of peripapillary RNFL in patients with mild POAG is lesser than in healthy subjects, and thickness in patients with moderate POAG is lesser than in patients with mild POAG, as well as in healthy subjects $(59.69 \pm 10.63 \mu \mathrm{m}$ vs $73.44 \pm 12.16 \mu \mathrm{m}$ vs $105.57 \pm 11.34 \mu \mathrm{m})$. Thickness of peripapillary RNFL in patients with preperimetric glaucoma is significantly lesser than in healthy subjects $(83.65 \pm 9.24 \mu \mathrm{m}$ vs $105.57 \pm 11.34 \mu \mathrm{m}$ ). Parameter S together with mean value of peripapillary RNFL thickness (AvgThic) is the best predictors of appearance and progression of preperimetric glaucoma. There is positive correlation between progression of glaucoma (MD value) and AvgThic. The best predictors of appearance and progression of glaucomatous disease are: AvgThic, RNFL thickness in quadrants- S, I, N; and parameters RNFL- Smax, Savg, lavg. ROC curve has shown that the following parameters are bad markers for progression of the disease: RNFL thickness in quadrant T and Imax.

Conclusions We concluded that the determination of thickness of peripapillary RNFL in patients with glaucoma using optical coherent tomography represents the method which distinguishes between patients with POAG, preperimetric glaucoma and healthy population hence it can be used in glaucoma diagnostics and follow-up.

\section{Background}

Primary open-angle glaucoma (POAG) represents a chronic, progressive and usually bilateral condition which, when left untreated, leads to blindness. It's characterized by, in a majority of cases, an increased intraocular pressure (IOP), excavation of the optic disc, visual field defects and an open anterior chamber angle [1].

The loss of optic nerve fibres is the most important characteristic of POAG and it can be quantified by measuring the thickness of peripapillary retinal nerve fibre layer (RNFL) [2]. During 1970s Hoyt et al. pointed out the importance of evaluation of RNFL thickness in diagnosis of glaucoma, at which time it was done strictly by ophthalmoscopy. This method had shown a positive correlation between the degree of damage to the RNFL on one side and the size of glaucomatous excavation and visual field defect on the other [3]. It was also shown that the thinning of RNFL can precede the defects in visual field [2,4] as the first sign of glaucoma pathology [5]. Despite the development of the semi-quantitative systems, evaluation of RNFL by ophthalmoscopy or photography is heavily influenced by examiner's experience and patient's cooperation, ultimately making them a subjective method [6]. Because of the need for objectification of changes in RNFL, optical coherence tomography (OCT) had been introduced in to the ophthalmology practice. It was developed at MIT (Massachusetts Institute of Technology) by David Huang et al. in James Fujimoto's laboratory in 1991. It is a non-invasive, non-contact, trans-pupillary method for scanning structures layer by layer, and like ultrasonography it is based on the principles of wave absorption and scattering, but uses light instead of ultrasound. Scanning of peripapillary RNFL is done with a fixed diameter (3.4 $\mathrm{mm})$ ring centred on the optic disc. After scanning, the software automatically calculates the thickness of the nerve fibre layer 360 degrees surrounding the optic disc, displaying the calculated values in graphs and tables. Results gathered in this way are highly reproducible and reliable [7-9].

The aim of this research was to: determine differences in RNFL thickness in patients with POAG and preperimetric glaucoma compared to the healthy population and to determine differences in RNFL thickness in patients with POAG relative to the

Page 2/13 
progression of the condition.

\section{Methods}

This research was prospective, analytic and observational in character, a case-control type of study. Based on the inclusion criteria, patients were included in the study and they underwent a complete ophthalmologic examination, visual field analysis (Humphrey visual field analyser, Carl Zeiss Meditec, Treshold program C 24-2) and optical coherence tomography of the peripapillary RNFL and the optic disc (Stratus OCT 3000, Carl Zeiss Meditec).

All peripapillary RNFL thickness measurements were done on the Stratus OCT 3000, Carl Zeiss Meditec apparatus, honouring the fast-scanning protocol for optical disc and peripapillary RNFL. After that, automatic analysis was applied using the previously implemented software version (3.0 Stratus OCT analysis software). Maximum of two scans of the peripapillary zone were used (with 3 consecutive scans), provided that the quality of the scan was equal to or higher than 7 . For data analysis, we picked the better one of the two scans.

120 patients over the age of 18 were included in this study. Pathology of only one eye of the patient was analysed and followed. In cases where both eyes of the patient met the inclusion criteria, the eye included in the study was randomly picked. Based on the clinical findings, four groups were formed:

First group (control-healthy) : 30 patients without glaucoma or other eye conditions, with best corrected visual acuity $\geq 0.9$, intraocular pressure (IOP) between $10 \mathrm{mmHg}$ and $21 \mathrm{mmHg}$, normal cup-to-disc ratio (C/D) and normal visual field finding, regardless of gender, race and ethnic background.

Second group (early glaucoma): 30 patients with POAG, with characteristic defects of the optic disc and RNFL, with a mean deviation $-2 \mathrm{~dB}<(\mathrm{MD})<-6 \mathrm{~dB}$ in standardized automated perimetry (Hodap classification), with characteristic glaucomatous visual field defects, without other eye conditions, without anamnestic data about previous laser or surgical intervention on the examined eye, with best corrected visual acuity $\geq 0.5$, regardless of gender, race and ethnic background.

Third group (moderate glaucoma): 30 patients with POAG, with characteristic defects of the optic disc and RNFL, with a mean deviation (MD) lower than $-6 \mathrm{~dB}$ and higher than $-12 \mathrm{~dB}$ in standardized automated perimetry (Hodap classification), without other eye conditions, without anamnestic data about previous laser or surgical interventions on the examined eye, with best corrected visual acuity $\geq 0.5$, regardless of gender, race and ethnic background.

The fourth group (pre-perimetric glaucoma): 30 patients with characteristic changes in the optic nerve head that represent glaucoma neuropathy, without functional outbreaks. The standard automated perimetry shows normal values of MD (from $2 \mathrm{~dB}$ to $+2.0 \mathrm{~dB}$ ), with the best corrected visual acuity $\geq 0.9$, regardless of the IOP.

The planned trial was performed on a patient at the anterior segment and glaucoma department, University Eye Clinic, Medical Faculty in Novi Sad, Clinical Center of Vojvodina in Novi Sad. We got an approval of the Ethics Committee of Eye Clinic, Clinical centre of Vojvodina and Teaching-Scientific Council of the Medical Faculty in Novi Sad, a written plan with text of informed consent and patient information was approved by the ethical commissions of the Medical Faculty in Novi Sad.

In our research descriptive statistics were used: arithmetic mean, standard deviation, median, quartiles, frequencies, and percentages. For the assessment of mean values of variables of two populations, the test for independent samples and the Man-Vitni test were used. An analysis of the variance and Kraskal-Volis test were used to compare the mean values of the variables of more populations. The correlation of categorical variables was examined using the $\chi 2$ test for the contour tables or by the Fischer test. The predictive quality of the variables on the outcome was evaluated using ROC curves. In all tests, the obtained level of statistical significance was expressed, statistically significant is considered to be $p<0.05$. The collected data was entered into a specially created database on a personal account, and the statistical processing was done using the SPSS for Windows. Results are displayed through charts and tables with a text commentary. 


\section{Results}

120 patients over the age of 18 were included in this study. Pathology of only one eye of the patient was analysed and followed. Based on the clinical findings and the inclusion criteria, four groups were formed. Each group encompassed an equal number of patients, thirty.

Gender distribution among patients is represented in table 1.

Table 1.Gender structure of the examinees

\begin{tabular}{|c|c|c|c|c|c|c|}
\hline Gender & \multicolumn{2}{|c|}{ Female } & \multicolumn{2}{c|}{ Male } & \multicolumn{2}{c|}{ Total } \\
\hline Group & $\mathrm{n}$ & $\%$ & $\mathrm{n}$ & $\%$ & $\mathrm{n}$ & $\%$ \\
\hline 1 & 22 & 73.33 & 8 & 26.67 & 30 & 100.00 \\
\hline 2 & 17 & 56.67 & 13 & 43.33 & 30 & 100.00 \\
\hline 3 & 13 & 43.33 & 17 & 56.67 & 30 & 100.00 \\
\hline 4 & 21 & 70.00 & 9 & 30.00 & 30 & 100.00 \\
\hline Total & 73 & 60.83 & 47 & 39.17 & 120 & 100.00 \\
\hline
\end{tabular}

In the total number of patients there were $73(60.83 \%)$ women and $47(39.17 \%)$ men. In the early POAG group there were 1.8 times more females, while the moderate POAG group had more male participants. In the total number of patients with POAG (groups 2 and 3 ) there was an equal number of males and females. Preperimetric group was characterised by $70 \%$ of female patients.

The number of patients within each age-group shown on graph 1.

\section{Graph 1 (PPT PICTURE 1)}

Majority of the patients belonged in the 50-59 years age-group (30\%), followed by $60-69$ years (26.6\%), while the least belonged to the group of under 30 years of age (6.6\%). In the eldest group (70+ years of age) there were 17 patients.

Minimal, maximal and average age value for each of the study groups is shown in table 2.

Table 2. Age of the patient

AM-arithmetic mean, SD-standard deviation

\begin{tabular}{|c|c|c|c|c|c|}
\hline Group & $\mathrm{N}$ & Min & Max & AS & SD \\
\hline 1 & 30 & 24 & 64 & 45.70 & 12.73 \\
\hline 2 & 30 & 37 & 79 & 60.13 & 13.16 \\
\hline 3 & 30 & 38 & 79 & 66.10 & 10.05 \\
\hline 4 & 30 & 27 & 71 & 51.80 & 9.54 \\
\hline Total & 120 & 24 & 79 & 55.93 & 13.77 \\
\hline
\end{tabular}

The average age of the patients in the whole sample was $55.93 \pm 13.77$ years. The youngest group was healthy group, then preperemetric group, then early POAG, and eldes was moderate POAG group. ANOVA showed that there is a statistically significant difference $(p<0.001)$ in average age of the patients between groups. 
The average values for each group: age of the patients, visual field parameters (MD, PSD) and RNFL quadrant thickness are presented in table 3.

Table 3. Differences in mean values of age, MD, PSD and RNFL thickness by quadrants between groups 1 and 2,1 and 3 , as well as 1 and 4.

p1-p-value between groups 1 and 2 (healthy and early POAG group)

p2-p-value between groups 1 and 3 (healthy and moderate POAG group)

p3-p-value between groups 1 and 4 (healthy and preperimetric glaucoma group)

\begin{tabular}{|c|c|c|c|c|c|c|c|c|c|c|c|}
\hline \multirow[t]{2}{*}{ Variable } & \multicolumn{2}{|c|}{ Healthy } & \multicolumn{2}{|c|}{ POAG-early } & POAG-1 & oderat & Preperime & glaucoma & \multirow[t]{2}{*}{$\mathrm{p} 1$} & \multirow[t]{2}{*}{$\mathrm{p} 2$} & \multirow[t]{2}{*}{ p3 } \\
\hline & Mean & $\pm \mathrm{SD}$ & Mean & $1 \pm S D$ & Mea & $\pm \mathrm{SD}$ & Mean \pm S & eviation & & & \\
\hline Age & 45.70 & 12.73 & 60.13 & 13.17 & 66.10 & 10.06 & 51.80 & 9.55 & $<0.001$ & $1<0.001$ & 0.040 \\
\hline $\mathrm{MD}$ & -0.29 & 0.70 & -4.18 & 1.27 & -9.89 & 1.74 & -0.80 & 1.01 & $<0.001$ & $1<0.001$ & 0.027 \\
\hline PSD & 1.40 & 0.53 & 4.34 & 1.72 & 9.08 & 2.02 & 1.92 & 0.76 & $<0.001$ & $1<0.001$ & 0.002 \\
\hline $\mathrm{S}$ & 124.37 & 717.89 & 84.63 & 18.46 & 68.93 & 19.59 & 91.67 & 14.21 & $<0.001$ & $1<0.001$ & $<0.001$ \\
\hline $\mathrm{N}$ & 90.53 & 22.53 & 62.70 & 15.47 & 54.53 & 16.84 & 59.83 & 19.52 & $<0.001$ & $1<0.001$ & $<0.001$ \\
\hline $\mathrm{I}$ & 133.47 & 715.38 & 87.27 & 22.48 & 69.23 & 23.97 & 113.87 & 19.11 & $<0.001$ & $1<0.001$ & $<0.001$ \\
\hline $\mathrm{T}$ & 73.73 & 13.71 & 55.90 & 16.12 & 46.50 & 10.85 & 70.63 & 20.52 & $<0.001$ & $1<0.001$ & 0.494 \\
\hline
\end{tabular}

The results of the RNFL thickness distribution by quadrants showed the highest values in the healthy group, followed by the preperimetric group, early POAG group, and the moderate POAG group. The highest average value of RNFL thickness was in the upper quadrant of the healthy group $(124.37 \pm 17.88 \mu \mathrm{m})$, and the lowest average value of RNFL thickness was in the temporal quadrant of the moderate POAG group $(46.50 \pm 10.852 \mu \mathrm{m})$. Other RNFL thickness values per quadrants are distributed between these two endpoints.

Table 4. Differences in mean values of RNFL thickness parameters between groups 1 and $2 ; 1$ and 3 ; and 1 and 4.

p1-p-value between groups 1 and 2 (healthy and early POAG group)

p2-p-value between groups 1 and 3 (healthy and moderate POAG group)

p3-p-value between groups 1 and 4 (healthy and preperimetric glaucoma group) 


\begin{tabular}{|c|c|c|c|c|c|c|c|c|c|c|c|}
\hline \multirow{2}{*}{$\begin{array}{c}\text { Variable } \\
\text { Imax/Smax }\end{array}$} & \multicolumn{2}{|c|}{$\begin{array}{c}\text { Healthy } \\
\text { Mean } \pm \text { SD }\end{array}$} & \multicolumn{2}{|c|}{$\begin{array}{l}\text { POAG-early } \\
\text { Mean } \pm \text { SD }\end{array}$} & \multicolumn{2}{|c|}{$\begin{array}{c}\text { POAG- } \\
\text { moderate } \\
\text { Mean } \pm \text { SD }\end{array}$} & \multicolumn{2}{|c|}{$\begin{array}{c}\text { Preperimetric } \\
\text { glaucoma } \\
\text { Mean } \pm \text { Std. } \\
\text { Deviation } \\
\end{array}$} & \multirow{2}{*}{$\begin{array}{c}\mathrm{p} 1 \\
\\
0.234\end{array}$} & \multirow{2}{*}{$\begin{array}{c}\mathrm{p} 2 \\
\\
0.084\end{array}$} & \multirow{2}{*}{$\begin{array}{c}\mathrm{p3} \\
\\
0.02\end{array}$} \\
\hline & 1.07 & 0.13 & 1.01 & 0.32 & 1.10 & 0.59 & 1.20 & 0.26 & & & \\
\hline Smax/Imax & 0.95 & 0.11 & 1.11 & 0.40 & 1.20 & 0.67 & 0.87 & 0.21 & 0.258 & 0.034 & 0.088 \\
\hline Smax/Tavg & 2.23 & 0.41 & 2.26 & 0.74 & 2.11 & 0.77 & 1.99 & 0.58 & 0.836 & 0.196 & 0.008 \\
\hline Imax/Tavg & 2.37 & 0.38 & 2.14 & 0.62 & 2.10 & 0.80 & 2.34 & 0.63 & 0.102 & 0.105 & 0.85 \\
\hline Smax/Navg & 1.87 & 0.47 & 1.93 & 0.62 & 1.88 & 0.68 & 2.40 & 1.05 & 0.756 & 0.941 & 0.057 \\
\hline Max-Min & 128.33 & 15.06 & 96.60 & 25.01 & 83.33 & 25.79 & 121.09 & 19.33 & $\begin{array}{c}< \\
0.001\end{array}$ & $\stackrel{<}{<}$ & 0.111 \\
\hline Smax & 160.13 & 17.21 & 117.20 & 25.04 & 94.07 & 28.62 & 128.57 & 21.76 & $\begin{array}{c}< \\
0.001\end{array}$ & $\begin{array}{c}< \\
0.001\end{array}$ & $\stackrel{<}{<}$ \\
\hline $\operatorname{Imax}$ & 169.83 & 14.56 & 113.00 & 25.72 & 95.13 & 29.74 & 150.10 & 22.11 & $\stackrel{<}{<}$ & $\stackrel{<}{<}$ & $\stackrel{<}{0.001}$ \\
\hline Savg & 124.30 & 17.88 & 84.17 & 17.72 & 68.70 & 18.86 & 92.17 & 15.59 & $\begin{array}{c}< \\
0.001\end{array}$ & $\begin{array}{c}< \\
0.001\end{array}$ & $\stackrel{<}{<01}$ \\
\hline Iavg & 135.60 & 18.10 & 87.00 & 21.71 & 69.57 & 23.50 & 113.00 & 17.79 & $\begin{array}{c}< \\
0.001\end{array}$ & $\begin{array}{c}< \\
0.001\end{array}$ & $\stackrel{<}{<01}$ \\
\hline AvgThic & 105.58 & 11.30 & 73.44 & 12.17 & 59.69 & 10.63 & 83.65 & 9.24 & $\begin{array}{c}< \\
0.001\end{array}$ & $\stackrel{<}{<}$ & $\stackrel{<}{<}$ \\
\hline
\end{tabular}

The Max-Min, Smax, Imax, Savg, lavg, and AvgThic parameters had the lowest values in the moderate POAG group, somewhat higher in the early POAG group, even higher in the preperimetric group and the highest in the group of healthy patients. Since AvgThic is the most commonly used parameter, its mean value for the healthy group was $105.57 \pm 11.34 \mu \mathrm{m}$, for the preperimetric glaucoma group was $83.65 \pm 9.24 \mu \mathrm{m}$, for the group of patients with early POAG was $73.44 \pm 12.16 \mu \mathrm{m}$, and for the group of patients with moderate POAG was $59.69 \pm 10.63 \mu \mathrm{m}$. The results of the analysis of the difference between the mean values of other RNFL parameters between the groups showed that for the parameters of Smax, Imax, Savg, lavg and AvgThic there wes statistically significant $(p<0,001)$ difference.

Pearson's correlation was analyzed in terms of the relationship between changes in MD values and the change in the values of RNFL thickness parameters (groups 2 to 3 and 1 to 4 ).

Table 5. Testing the relationship between groups: 2 and 3, 1 and 4 in relations to the RNFL thickness parameters changes

\begin{tabular}{|c|c|c|c|c|c|c|c|c|c|c|c|c|c|c|c|}
\hline & S & $\mathrm{N}$ & I & $\mathrm{T}$ & $\begin{array}{l}\text { Imax } \\
\text { /Smax }\end{array}$ & $\begin{array}{c}\text { Smax/ } \\
\text { Imax }\end{array}$ & $\begin{array}{c}\text { Smax/ } \\
\text { Tavg }\end{array}$ & $\begin{array}{l}\text { Imax/ } \\
\text { Tavg }\end{array}$ & $\begin{array}{l}\text { Smax/ } \\
\text { Navg }\end{array}$ & $\begin{array}{l}\text { Max- } \\
\text { Min }\end{array}$ & Smax & Imax & Savg & Iavg & $\begin{array}{l}\text { Avg } \\
\text { Thic }\end{array}$ \\
\hline $\begin{array}{c}\text { Pearson } \\
\text { corelation } \\
(2-3) \\
\end{array}$ & 0.418 & 0.207 & 0.421 & 0.397 & -0.093 & -0.086 & 0.071 & 0.021 & 0.106 & 0.276 & 0.422 & 0.348 & 0.432 & 0.406 & 0.571 \\
\hline $\mathrm{p}$ & 0.001 & 0.112 & 0.001 & 0.002 & 0.482 & 0.515 & 0.591 & 0.873 & 0.421 & 0.033 & 0.001 & 0.006 & 0.001 & 0.001 & 0.0005 \\
\hline $\begin{array}{c}\text { Pearson } \\
\text { corelation } \\
\quad(1-4)\end{array}$ & -0.717 & -0.595 & -0.498 & -0.09 & 0.303 & -0.223 & -0.238 & -0.025 & 0.314 & -0.208 & -0.633 & -0.472 & -0.698 & -0.539 & -0.734 \\
\hline $\mathrm{p}$ & 0.001 & 0.001 & 0.001 & 0.494 & 0.019 & 0.087 & 0.067 & 0.85 & 0.015 & 0.111 & 0.001 & 0.001 & 0.001 & 0.001 & 0.0005 \\
\hline
\end{tabular}

By Pearson's correlation the medium positive relationship was found between the MD values and the following parameters of the RNFL thickness: S, I, T, Smax, Imax, Savg, lavg, AvgThic between groups 2 and 3. The highest statistical connection ( $p$ $<0.0005)$ had AvgThic parameter, and high significant statistical connections had parameters: S, I, Smax, Savg, lavg (p 
$<0.001)$. By Pearson's correlation it was found that there is a strong negative relationship between groups 1 and 4 and the AvgThic parameter. There was a medium negative relationship with the parameters Savg, lavg, Imax, Smax.

The results of determining potential predictors for disease progression are shown in Graph 2. The surfaces determined by Receiver Operating Characteristic (ROC) curves, cut-off, sensitivity and specificity and p-values for each individual parameter are displayed.

\section{Graph 2 (PPT PICTURE 2)}

ROC curves of the RNFL thickness in quadrants show that the parameters $S$ and I are good predictors for disease progression. The parameter $S$ have surface of the curve area of $0.736(p=0.002)$, the sensitivity is $63.3 \%$ and the specificity is $73.3 \%$. For the parameter $I$, the surface of the curve is $0.733,(p=0.002)$, the sensitivity is $70 \%$ and the specificity is $73.3 \%$. ROC curve shows that variable $\mathrm{T}$ is a bad predictor for the onset of disease progression.

Table 6. Determination of POAG progression predictor

\begin{tabular}{|c|c|c|c|c|c|}
\hline Variable & Surfice area & Cut-off & Sensitivity (\%) & Specificity (\%) & $\mathrm{p}$ \\
\hline $\mathrm{S}$ & 0.736 & 75.00 & 63.3 & 73.3 & 0.002 \\
\hline $\mathrm{I}$ & 0.733 & 76.00 & 70.0 & 73.3 & 0.002 \\
\hline $\mathrm{T}$ & 0.676 & 54.00 & 80.0 & 53.3 & 0.019 \\
\hline Max-Min & 0.637 & $/$ & $/$ & $/$ & 0.069 \\
\hline Smax & 0.727 & 102.50 & 60.0 & 76.7 & 0.002 \\
\hline Imax & 0.678 & 96.00 & 63.3 & 80.0 & 0.018 \\
\hline Savg & 0.728 & 75.00 & 60.0 & 73.3 & 0.002 \\
\hline Iavg & 0.736 & 76.5 & 73.3 & 73.3 & 0.002 \\
\hline AvgThic & 0.803 & 63.945 & 70.0 & 83.3 & $<0.0005$ \\
\hline
\end{tabular}

The ROC curve showed that the parameters: S, I, Smax, Savg, lavg, AvgThic are good predictors for disease progression in patients with POAG. Other analysed parameters are poor pre-indicators. AvgThic is the best predictor for disease progression ( $p<0.0005)$. Cut-off value for AvgThic is 63.945 ; Sensitivity is $67 \%$ and the specificity is $83.3 \%$.

\section{Discussion}

Even though gender is not considered as a risk factor for developing POAG, Framigham, Barbados, Blue Mountains and other studies [10-12] have shown that a greater number of males than females suffer from POAG. Gender analysis of our 120 study participants shows that, in the whole sample, the majority of participants were females (60\%). Only the moderate POAG group had more males (56.67\%). However, if we look only at the patients with early and moderate POAG, there is an equal number of males and females. The average age in the whole sample was $55.93 \pm 13.77$ years. The eldest group was the moderate POAG group with an average of $66.1 \pm 10.05$ years, while the youngest one was the healthy group with an average of $45.7 \pm 12.73$ years. In the Kanamori et al. [8] study, the mean age of the patients was $53,11 \pm 7,76$ years with a similar distribution between groups.

Analysis of average values of the MD visual field parameter showed that a statistically significant decrease happens going from the healthy group to the moderate POAG group. Testing of differences between MD and PSD values among groups (ANOVA) and Post-Hoc (Tukey) analysis had shown that there is a statistically significant difference between the groups $(p<0.001)$. This had shown that MD and PSD values completely separate groups 1, 2 and 3 . The search of Sahli et al. [9] as well as some other's researchers [2,13-16] have shown a high correlation between MD values and the degree of POAG progression. 
The mean value of RNFL thickness for the healthy group in our study was $105.57 \pm 11.34 \mu \mathrm{m}$, which was the highest value compared to other groups. The lowest value of RNFL thickness was in the moderate POAG group (59.6 9 $\pm 10.63 \mu \mathrm{m})$. RNFL thickness value decreases with the progression of POAG, which is confirmed by the statistical analysis of the RNFL thickness parameter (AvgThic) differences between groups $(p<0.0005)$.

The results obtained by measuring RNFL thickness in quadrants $(S, N, I, T)$ showed the same distribution in all study groups. RNFL thickness value was found to be the highest in the inferior quadrant, second highest in the superior quadrant, third highest in the nasal quadrant, while it was the lowest in the temporal quadrant. Also, it was shown that the rule of distribution of average RNFL thickness between groups is also applicable to RNFL thickness by quadrants. In all of the quadrants, the greatest RNFL thickness was found in the healthy group and the lowest in the moderate POAG group. Histologic studies done on enucleated eyes [17], as well as studies done on patients [18,8] have practically shown that the distribution of RNFL thickness by quadrants is a routine occurrence which follows the ISNT rule. Research by Savini et al. [19] from 2005 has shown that the average RNFL thickness in healthy individuals is $101.52 \pm 11.09 \mu \mathrm{m}$, with the quadrant RNFL thickness distribution: for temporal quadrant $69.94 \pm 13.17 \mu \mathrm{m}$, for superior $124.29 \pm 16.59 \mu \mathrm{m}$, for nasal $81.24 \pm 17.95 \mu \mathrm{m}$ and for inferior $129.8 \pm 19.26 \mu \mathrm{m}$. Kanamori et al. [8] have shown that the thinning of RNFL by quadrants follows the progression of glaucomatous disease. The high congruence between the results of our research and others, both in average values and quadrant distribution, confirms that the RNFL is the thickest in the inferior quadrant and the thinnest in the temporal quadrant.

Mwanza et al. [20] reported that in initial POAG focal loss of RNFL thickness is in the lower quadrant, while Nouri-Mahdavi et al. [21] analysing OCT finding among healthy group and 59 patients from the early POAG group came to the conclusion that the best discriminating RNFL thickness parameter is the upper quadrant.

The possibility of detecting glaucoma at an early preperimetric stage was confirmed by the study of Sihota et al. [16], and it has particularly emphasized AvgThic as parameter indicating the onset of the disease. Guedes et al. [22] studied the ability of early detection of glaucoma by the OCT apparatus. They compared the changes that occur in the thickness of the macular zone and the peripapillary RNFL zone and concluded that in the competition of numerous parameters, the average thickness of RNFL is far the best in discriminating against patients with early glaucoma. As a cause of this, they hinted that there are almost $100 \%$ ganglia retinal cells in the peripapillary zone, and in the macular zone their number is about $50 \%$, and the parameters of the thickness of RNFL are better for determining glaucoma than the parameters of the macular region. The area of ROC curve for AvgThic RNFL was 0.93 in this study, which was higher than the results obtained in our study (0.803).

Receiver Operating Characteristic (ROC) curves were designed to show which parameter could be a good predictor for disease progression, with which sensitivity and with which specificity. A study by Parikh et al. [23] showed that the best chance of discriminating against healthy glaucoma patients has a parameter RNFL thickness in inferior quadrant with sensitivity of $67 \%$ and specificity of $84 \%$. The best parameter of the RNFL thickness group is AvgThic with a largest area of ROC curve (Area = 0.803 ), cut-off value 63.945 , sensitivity $67 \%$, and specificity $83.3 \%$ which are almost the same results as ours. Leite et al. [24] reported that the largest area below the ROC were at AvgThic, quadrant I and S. Analyzing the ROC curves of Savini et al. [19], it is seen that AvgThic is the best marker for the occurrence of glaucoma with the largest area under the curve (Area $=0.725)$, then the quadrant $S$ (Area $=0.672)$, the quadrant I (Area $=0.655)$ and the worst $N$ (Area $=0.564)$ which is confirmed by the results of our study. Sahli et al. [9] also confirmed that the surface of the ROC is the highest in AvgThic and quadrant I (Area = 0.824 , Area $=0.822$ ). A slightly smaller area was in the case of quadrant $S$, but therefore high values were $77 \%$ sensitivity and $87 \%$ specificity.

\section{Conclusion}

Based on the results obtained in this research it can be concluded that the thickness of RNFL in patients with POAG and preperimetric glaucoma are statistically significantly lower compared to healthy population. There is a positive correlation between the stage of the disease and the average RNFL thickness. All parameters of the RNFL thickness monitor the change in MD values except Imax/Smax, Smax/Imax, Smax/Tavg, Imax/Tavg, Smax/Navg, quadrant N thicknes and they cannot be 
used in monitoring glaucoma progression. Parameters: AvgThic, S, I, Smax, Savg, lavg are excellent predictors of glaucoma occurence and progression. ROC curve has shown that we can use these parameters, especially AvgThic with high specificity and sensitivity in glaucoma monitoring. Finally, optical coherence tomography represents a method which distinguishes between patients with POAG, preperimetric glaucoma and healthy population hence it can be used in glaucoma diagnostics and follow-up.

\section{Declarations}

- Ethics approval and consent to participate: Ethics Committee of Eye Clinic, Clinical centre of Vojvodina and TeachingScientific Council of the Medical Faculty in Novi Sad at the session held on 24.08.2015. unanimously gave its consent to the conduct of research titled "Peripapillary retinal nerve fibre thickness in patients with primary open-angle glaucoma" to be performed by MD Aleksandar Miljkovic and confirms that the survey is in accordance with the Declaration of Helsinki. Consent to participate was obtained in written form by all study participants.

- Consent for publication - not applicable.

- Availability of data and materials- The datasets used and analysed during the current study is attached as suporting file an if other analyses or statistical steps are needed they are available from the corresponding author on reasonable request.

- Competing interests - The authors declare that they have no competing interests.

- Funding-nothing to declare.

- Authors' contributions:

- Aleksandar Miljkovic- substantial contributions to the conception and design of the study, patient screening, analysis, interpretation of data, the creation of new software used in the work, discussion results and conclusions.

- Nikola Babic - contribution to study design, group formation, analysis and statistical data processing, help with the literature and conclusions.

- Sofija Davidovic - contributions to the conception, assistance with patient screening, contribution to the collection of literature and in particular to the comparison of the obtained data with the literature.

- Sava Barisic - contribution to acquisition and analysis, check all the findings obtained with the OCT apparatus, their quality, reliability and reproducibility. Entering all data into EXCEL tables and checking the accuracy of the data entered, help with discussion and the literature.

- Jelena Ljikar - assistance with patient screening, data collection and sorting, analysis and interpretation of data of results.

- Sandra Jovanovic - contribution to study design, correction of errors in text, methodology, interpretation of data, discussion results and conclusions.

- Acknowledgements - not applicable

\section{References}

1. Van Buskirk EM, Cioffi GA. Glaucomatous optic neuropathy. Am J Ophthalmol. 1992; 113(4):447-452.

2. Sommer A, Katz J, Quigley HA, Miller NR, Robin AL, Richter RC, Witt KA. Clinically detectable nerve fiber atrophy precedes the onset of glaucomatous field loss. Arch Ophthalmol 1991; 109(1):77-83.

3. Quigley HA, Katz J, Derick RJ, Gilbert D, Sommer A. An evaluation of optic disc and nerve fiber layer examinations in monitoring progression of early glaucoma damage. Ophthalmology 1992;99(1):19-28.

4. Airaksinen PJ, Mustonen E, Alanko HI. Optic disc haemorrages precede retinal nerve fiber layer defects in ocular hypertension. Acta Ophthalmol 1981; 59(5):627-41.

5. Quigley HA, Addicks EM. Quantitative studies of retinal nerve fiber layer defects. Arch Ophthalmol 1982; 100(5):807-14.

6. Pollock SC, Miller NR. The retinal nerve fiber layer. Int Ophthalmol Clin 1986; 26(4):201-21. 
7. Huang D, Swanson EA, Lin CP, Schuman JS, Stinson WG, Chang W, et al. Optical coherence tomography. Science 1991; 254(5035):1178-81.

8. Kanamori A, Nakamura M, Escano MF, Seya R, Maeda H, Negi A. Evaluation of the glaucomatous damage on retinal nerve fiber layer thickness measured by optical coherence tomography. Am J Ophthalmol. 2003;135(4):513-20.

9. Sahli E, Tekeli O. Evaluation of retinal nerve fiber layer thickness with spectral domain oct in primary open angle glaucoma and ocular hypertension. J Clin Exp Ophthalmol 2012; 3:2-5.

10. Medeiros FA, Zangwill LM, Bowd C, Vessani RM, Susanna R Jr, Weinreb RN. Evaluation of retinal nerve fiber layer, optic nerve head, and macular thickness measurements for glaucoma detection using optical coherence tomography. Am $J$ Ophthalmol. 2005; 139(1):44-55.

11. Hoh ST, Greenfield DS, Mistlberger A, Liebmann JM, Ishikawa H, Ritch R. Optical coherence tomography and scanning laser polarimetry in normal, ocular hypertensive, and glaucomatous eyes. Am J Ophthalmol. 2000; 129:129-135.

12. Leung CK, Chan WM, Yung WH, Ng AC, Woo J, Tsang MK, Tse RK. Comparison of macular and peripapillary measurements for the detection of glaucoma: an optical coherence tomography study. Ophthalmology 2005; 112(3):391-400.

13. Kazuyuki H, Saki M, Kaori T, Eri N, Shino S, Akitaka T. Use of the structure-function relationship in detecting glaucoma progression in early glaucoma. BMC Ophthalmology 2014 14:118.

14. Li S, Wang X, Li S, Wu G, Wang N. Evaluation of optic nerve head and retinal nerve fiber layer in early and advance glaucoma using frequencydomain optical coherence tomography. Graefes Arch Clin Exp Ophthalmol 2010; 248: 429434.

15. Mok KH, Lee VW, So KF. Retinal nerve fiber loss pattern in high-tension glaucoma by optical coherence tomography. J Glaucoma. 2003;12(3):255-259.

16. Sihota R, Sony P, Gupta V, Dada T., Singh R. Diagnostic capability of optical coherence tomography in evaluating the degree of glaucomatous retinal nerve fiber damage. Invest Ophthalmol Vis Sci 2006; 47: 2006-10.

17. Dichtl A, Jonas I, Naumann GO. Retinal nerve fiber layer thickness in human eyes. Graefes Arch Clin Exp Ophthalmol 1999; 237(6):474-9.

18. Budde WM, Jonas JB, Martus P, Grunder AE. Influence of optic disc size on neuroretinal rim shape in healthy eyes. $J$ Glaucoma 2000; 9(5):357-62.

19. Savini G, Zanini M, Carelli V, Sadun AA, Ross-Cisneros FN, Barboni P. Correlation between retinal nerve fibre layer thickness and optic nerve head size: an optical coherence tomography study. Br J Ophthalmol 2005; 89(4):489-92.

20. Mwanza JC, Chang RT, Budenz DL, Durbin MK, Gendy MG, et al. Reproducibility of peripapillary retinal nerve fiber layer thickness and optic nerve head parameters measured with cirrus HD-OCT in glaucomatous eyes. Invest Ophthalmol Vis Sci 2010; 51: 5724-5730.

21. Nouri-Mahdavi K, Hoffman D, Tannenbaum DP, Law SK, Caprioli J. Identifying early glaucoma with optical coherence tomography. Am J Ophthalmol 2004; 137:228-35.

22. Guedes V, Schuman JS, Hertzmark E, Wollstein G, Correnti A, Mancini R, Lederer D, Voskanian S, Velazquez L, Pakter HM, Pedut-Kloizman T, Fujimoto JG, Mattox C. Optical coherence tomography measurement of macular and nerve fiber layer thickness in normal and glaucomatous human eyes. Ophthalmology 2003; 110:177-89.

23. Parikh R, Parikh S, Kothari K. Optic nerve head and retinal nerve fiber layer imaging in glaucoma diagnosis. J Curr Glaucoma Pract 2009; 3(2):8-19.

24. Leite MT, Zangwill LM, Weinreb RN, Rao HL, Alencar LM, Sample PA, Medeiros FA. Effect of disease severity on the performance of Cirrus spectral-domain OCT for glaucoma diagnosis. Invest Ophthalmol Vis Sci 2010; 51:4104-09.

\section{Abbreviations}

RNFL - retinal nerve fiber layer 
POAG - primary open-angle glaucoma

AvgThic - average thickness

MD - mean deviaton

ROC - Receiver operating characteristic

IOP - intraocular pressure

OCT - Optical coherence tomography

MIT - Massachusetts Institute of Technology

S - superior

I- inferior

$\mathrm{T}$ - temporal

$N$ - nasal

Max-Min - minimal minus maximal

Smax - superior maximal

Imax - inferior maximal

Savg - superior average

lavg - inferior average

Tavg - temporal average

Navg - nasal average

Figures 


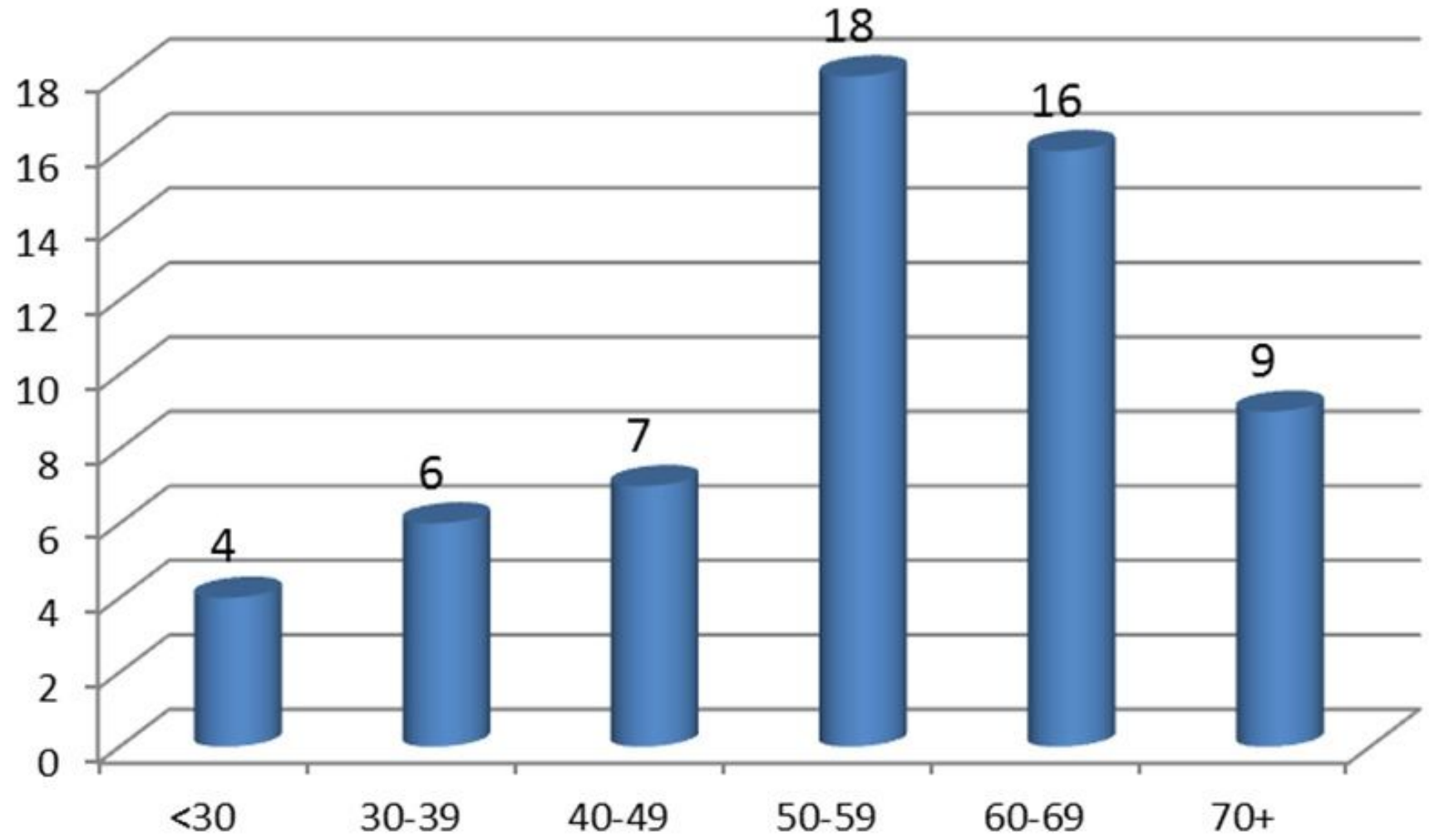

Figure 1

Graphical presentation of the patient according to age groups

ROC Curve

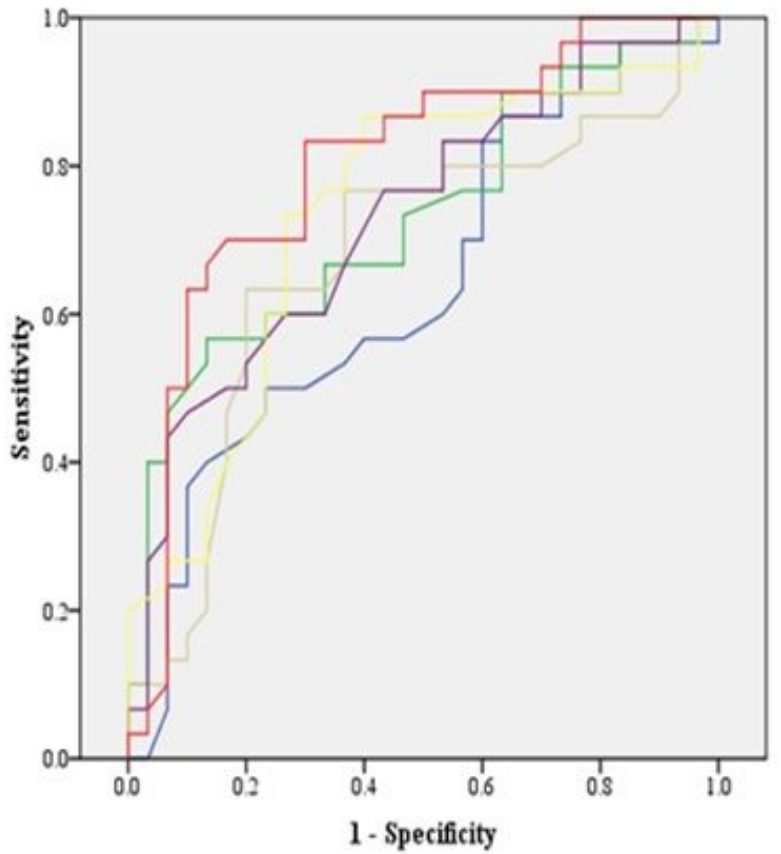

ROC Curve

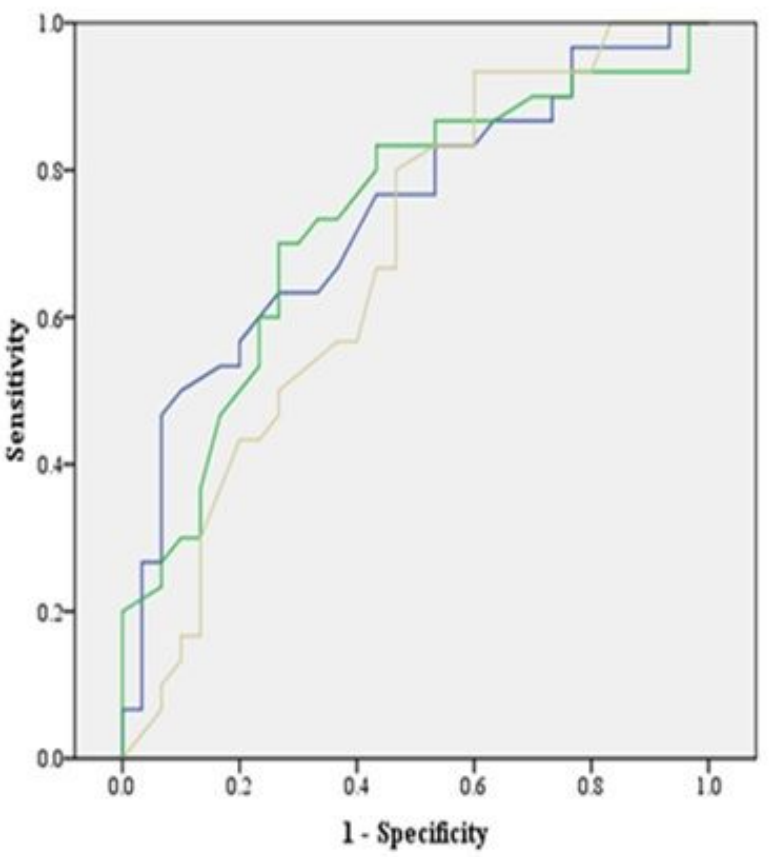

Figure 2

Graphical presentation of ROC curves for the RNFL thickness parameters 


\section{Supplementary Files}

This is a list of supplementary files associated with this preprint. Click to download.

- Copyof120patinetsRNFLandPNOstatistics.xls 